\title{
Two New Prenylated Xanthones from the Bark of Garcinia xanthochymus
}

\author{
Yu Chen, ${ }^{\dagger}$ Guang-zhong Yang, ${ }^{\dagger, *, *}$ Fang-fang Zhong, ${ }^{\dagger}$ and Hong-wu He ${ }^{\dagger, *}$ \\ ${ }^{\dagger}$ Key Laboratory of Pesticide and Chemical Biology, Ministry of Education, Central China Normal University, \\ 152 Luoyu Road, Wuhan 430079, P. R. China. "E-mail: he1208@mail.ccnu.edu.cn \\ State Key Laboratory of Drug Research, Shanghai Institute of Materia Medica, Chinese Academy of Sciences, \\ Shanghai 201203, P. R. China \\ ${ }^{\star}$ Laboratory for Natural Product Chemistry, College of Pharmacy, South Central University for Nationalities, \\ Wuhan 430074, P. R. China. ${ }^{*}$ E-mail: yanggz888@126.com \\ Received July 23, 2010, Accepted September 2, 2010
}

Key Words: Xanthones, Garcinia, Garcinia xanthochymus

Extensive phytochemical studies have shown that Garcinia species are rich in a variey of oxygenated and prenylated xanthones. ${ }^{1}$ Xanthone are class of polyphenolics that exhibit welldocumented pharmacological properties, such as antioxidative, antileukaemic, antitumour, antiulcer, antimicrobial, antihepatotoxic, and CNS depressant activities, ${ }^{2}$ mainly due to their oxygenated heterocyclic nature and diversity of functional groups. ${ }^{3}$ The leaves, seeds, fruits, twig bark, and wood of G. xanthochymus were previously reported to contain benzophenones, ${ }^{4}$ flavonoids, ${ }^{5}$ triterpenes ${ }^{6}$ and xanthones. ${ }^{7}$ As a continuation of our efforts to purse the active natural products from G. xanthochymus, two new xanthones (1) and (2), together with 12 known xanthones were isolated by repeated column chromatography from the EtOAc fraction of the ethanolic extract of G. xanthochymus gathered in Yunnan province of China. The structures of twelve known compounds 3-14 were elucidated as subelliptenone $\mathrm{H} \mathrm{(3)},{ }^{8}$ ananixanthone (4), ${ }^{9}$ pyranojacareubin $(\mathbf{5}),{ }^{10}$ rheediaxanthone $\mathrm{A}(\mathbf{6}),{ }^{11}$ toxyloxanthone $(7),{ }^{12}$ 6-deoxyisojacareubin $(\mathbf{8}),{ }^{13}$ atroviridin $(\mathbf{9}),{ }^{14}$ 6-deoxyjacareubin $(\mathbf{1 0}),{ }^{15}$
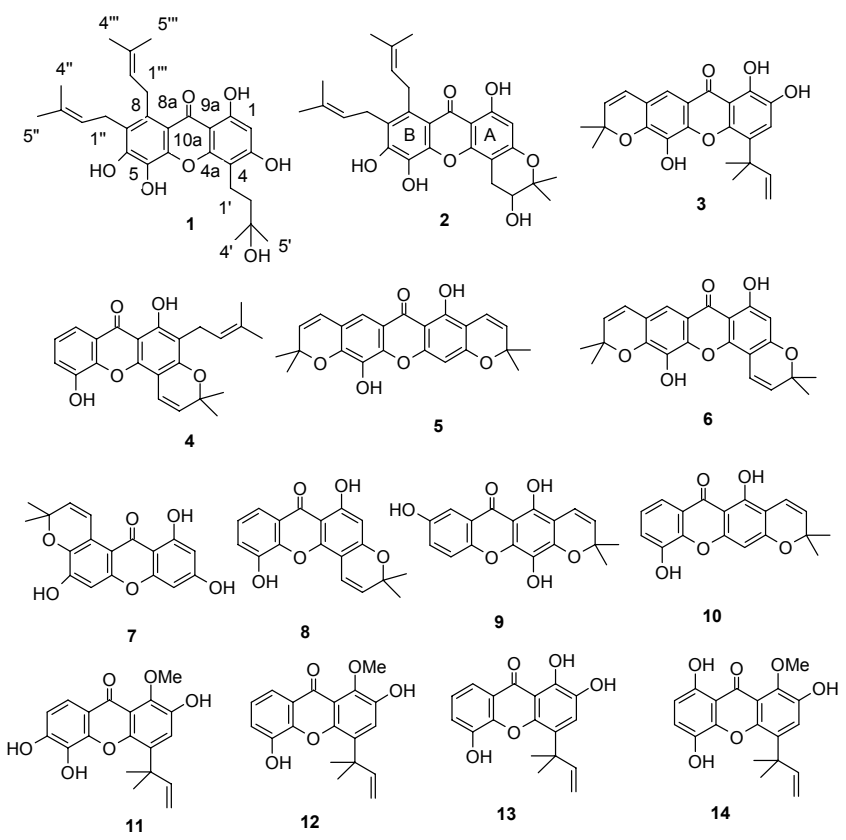

12

1-O-methylsymphoxanthone (11),${ }^{16} 1-O$-methylglobuxanthone (12), ${ }^{17}$ globuxanthone $(\mathbf{1 3}),{ }^{18}$ and garciniaxanthone $\mathrm{H}(\mathbf{1 4})^{19}$ by interpreting the NMR spectroscopic data and comparing those data with the published values. In this paper, we reported the isolation and structural elucidation of two new xanthones (1) and (2) using spectroscopic evidence.

Compound $\mathbf{1}$ was obtained as a yellow powder, and its molecular formula was assigned as $\mathrm{C}_{28} \mathrm{H}_{34} \mathrm{O}_{7}$ by the molecular ion peak at $m / z 482.2301$ in the HREIMS. Its UV absorptions at 230,265 , and $346 \mathrm{~nm}$ suggested a xanthone skeleton as its base structure. The ${ }^{1} \mathrm{H}$ NMR spectrum of $\mathbf{1}$ revealed the presence of a hydrogen-bonded hydroxyl group [ $\left.\delta_{\mathrm{H}} 13.41(1 \mathrm{H}, \mathrm{s})\right]$, one aromatic proton $\left[\delta_{\mathrm{H}} 6.27(1 \mathrm{H}, \mathrm{s})\right]$, two 3-methyl-2-butenyl groups $\left[\delta_{\mathrm{H}} 3.46(2 \mathrm{H}, \mathrm{d}, J=6.3 \mathrm{~Hz}), 5.09(1 \mathrm{H}, \mathrm{br} \mathrm{s}), 1.79(3 \mathrm{H}, \mathrm{s})\right.$, $1.67(3 \mathrm{H}, \mathrm{s}), 4.11(2 \mathrm{H}, \mathrm{d}, J=5.7 \mathrm{~Hz}), 5.09(1 \mathrm{H}, \mathrm{br} \mathrm{s}), 1.79(3 \mathrm{H}$, $\mathrm{s})$, and $1.67(3 \mathrm{H}, \mathrm{s})]$, and a 3-hydroxy-3-methylbutyl group $\left[\delta_{\mathrm{H}}\right.$ $2.98(2 \mathrm{H}, \mathrm{m}), 1.79(2 \mathrm{H}, \mathrm{m})$, and $1.33(6 \mathrm{H}, \mathrm{s})]$. The ${ }^{13} \mathrm{C}$ NMR spectrum showed 28 carbon signals, including 6 methyl, 4 methylene, 3 methine and 15 quaternary carbons by analysis of the DEPT spectra. The NMR data of $\mathbf{1}$ was similar to those of 1,3,5,6-tetrahydroxy-4,7,8-tri(3-methyl-2-butenyl)xanthone, ${ }^{\text {7a }}$ a xanthone isolated from the same plant except that a 3-methyl2-butenyl group of the latter was replaced in 1 by 3-hydroxy3-methylbutyl group. The substituents on the xanthone skeleton were determined on the basis of the HMBC spectral analysis (Fig. 2). The locations of the two 3-methyl-2-butenyl groups were placed at the $\mathrm{C}-7$ and $\mathrm{C}-8$ positions by the HMBC correlations of $\mathrm{H}_{2}-1 " / \mathrm{C}-6\left(\delta_{\mathrm{C}} 149.4\right), \mathrm{C}-7\left(\delta_{\mathrm{C}} 125.6\right)$, and C-8 $\left(\delta_{\mathrm{C}} 134.2\right)$ and $\mathrm{H}_{2}-1 " 1 / \mathrm{C}-7\left(\delta_{\mathrm{C}} 125.6\right), \mathrm{C}-8\left(\delta_{\mathrm{C}} 134.2\right)$, and C-8a $\left(\delta_{\mathrm{C}} 111.4\right)$. The remaining 3-hydroxy-3-methylbutyl group was located at $\mathrm{C}-4$ based on the HMBC correlations of $\mathrm{H}_{2}-1^{\prime} / \mathrm{C}-3\left(\delta_{\mathrm{C}} 162.1\right)$, $\mathrm{C}-4\left(\delta_{\mathrm{C}} 107.3\right)$, and $\mathrm{C}-4 \mathrm{a}\left(\delta_{\mathrm{C}} 154.3\right)$. Therefore, the structure
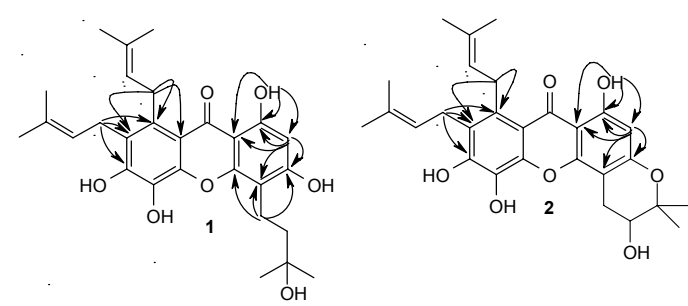

Figure 2. Significant HMBC correlations of compounds $\mathbf{1}$ and $\mathbf{2}$.

Figure 1. The structures of compounds 1-14. 
of 1 was established to be 1, 3, 5, 6-tetrahydroxy-4-(3-hydroxy3-methylbutyl)-7,8-di-(3-methyl-2-butenyl) xanthone.

Compound 2 was obtained as a yellow powder. The molecular formula was determined as $\mathrm{C}_{28} \mathrm{H}_{32} \mathrm{O}_{7}(\mathrm{~m} / z$ 480.2147) by HREIMS. Comparing its ${ }^{13} \mathrm{C}$ NMR and DEPT data with those of $\mathbf{1}$, it was found that compound $\mathbf{2}$ had almost the same chemical shifts as those of 1, except for one 2,2-dimethyl-3-hydroxydihydropyran ring carbon signals at $\delta_{\mathrm{c}} 29.3(\mathrm{t}), 68.6(\mathrm{~d}), 79.2$ (s), 20.7 (q), and 25.5 (q) in 2 instead of 3-hydroxy-3-methylbutyl carbon signals at $\delta_{\mathrm{c}} 16.9(\mathrm{t}), 42.3(\mathrm{t}), 71.4(\mathrm{~s})$, and $28.9(\mathrm{q})$ in 1. These facts suggested that 2,2-dimethyl-3-hydroxydihydropyran ring in the structure of 2 replaced 3-hydroxy-3methylbutyl group found in $\mathbf{1}$. The HMBC correlations between $\mathrm{H}_{2}-1 " / \mathrm{C}-6\left(\delta_{\mathrm{C}} 150.6\right), \mathrm{C}-7\left(\delta_{\mathrm{C}} 125.9\right)$, and $\mathrm{C}-8\left(\delta_{\mathrm{C}} 135.1\right)$ and $\mathrm{H}_{2}-1 " \mathrm{C}-7\left(\delta_{\mathrm{C}} 125.9\right), \mathrm{C}-8\left(\delta_{\mathrm{C}} 135.1\right)$, and C-8a $\left(\delta_{\mathrm{C}} 111.8\right) \mathrm{su}-$ ggested that two prenyl groups were located at C-7 and C-8, respectively. The position of 2,2-dimethyl-3-hydroxydihydropyran ring was determined as follow. In the ${ }^{13} \mathrm{C}-\mathrm{NMR}$ spectrum, the aromatic carbons with an oxygen function were observed at $\delta_{\mathrm{c}} 161.7,160.2$, and 154.3, which suggested the presence of a 1,3,5-trioxygenated benzene ring in partial structure $\mathrm{A}$. The HMBC of H-2 $\left[\delta_{\mathrm{H}} 6.09(1 \mathrm{H}, \mathrm{s})\right]$ showed correlations to C-9a, $\mathrm{C}-1$, an oxygenated aromatic carbon $\left(\delta_{\mathrm{C}} 160.2\right)$ and a substituted aromatic carbon $\left(\delta_{\mathrm{C}} 98.7\right)$. Thus, the carbon signals at $\delta_{\mathrm{C}} 160.2$ and $\delta_{C} 98.7$ were assigned to $C-3$ and C-4, respectively. The 2,2dimethyl-3-hydroxydihydropyran ring should be fused at C-3 and C-4 of the xanthone nucleus with an ether linkage at C-3. Therefore, 2 was assigned as 3,4-dihydro-3,6,7,11-tetrahydroxy8,9-di-(3-methyl-2-butenyl)-2,2-dimethyl-pyrano-[2,3-c] xanthone.

Compounds $\mathbf{1}$ and $\mathbf{2}$ were evaluated for their antimicrobial activities in broth microdilution bioassay. ${ }^{20}$ Compound $\mathbf{2}$ displayed moderate activity against Candida tropicalis with MICs $8.13 \mu \mathrm{M}$ using nystatin as a positive control $(\mathrm{MIC}=0.53 \mu \mathrm{M})$. Compound 1 was inactive against tested fungi.

\section{Experimental Section}

Reagent and equipment. Thin-layer chromatography (TLC): Pre-coated silica gel $G_{254}$ plates (Qingdao Haiyang Chemical Co., Ltd., P. R. China). Column Chromatography (CC): Silica gel (200 - 300 mesh; Qingdao Haiyang Chemical Co., Ltd., P. R. China) and $\mathrm{C}_{18}$ reversed-phase silica gel (YMC CO., LTD., Japan). UV spectral: SP-2102UVPC spectrometer using MeOH as the solvent. ${ }^{1} \mathrm{H}$ - and ${ }^{13} \mathrm{C}$-NMR spectral: Bruker-AM-400 instrument (Bruker company, Massachusetts, USA); $\delta$ in ppm rel. to $\mathrm{SiMe}_{4}$ as internal standard ( $\left.=0 \mathrm{ppm}\right), J$ in Hz. EI-MS: Finnigan -MAT-95 mass spectrometer (Finnigan company; UK) (70 ev); in $m / z$ (rel. \%).

Plant material. The bark of G. xanthochymus was collected from Xishuangbanna Prefecture, Yunnan Province, P. R. China and identified by Xishuangbanna Prefecture National Medicine Research Institute. The voucher specimen (06061201) was deposited with the Herbarium of College of Pharmacy, South Central University for Nationalities.

Extraction and isolation. The powdered bark of G. xanthochymus $(6.5 \mathrm{~kg})$ was extracted with $95 \% \mathrm{EtOH}$ and then successively partitioned with petroleum ether (P.E.) $(3.0 \mathrm{~L} \times 3)$,
EtOAc $(3.0 \mathrm{~L} \times 3)$, and $n-\mathrm{BuOH}(3.0 \mathrm{~L} \times 3)$. The combined extract of EtOAc $(590 \mathrm{~g})$ was chromatographed on silica gel with P.E-Me ${ }_{2} \mathrm{CO}(9: 1,8: 2,7: 3,1: 1,3: 7$, and $0: 1, v / v)$ to give thirteen fractions (fr.1 - fr.13). After repeated silica gel (cyclohexane- $\mathrm{Me}_{2} \mathrm{CO}, 95: 1 \rightarrow 0: 1$ gradient system) and $\mathrm{RP}-18(\mathrm{MeOH}-$ $\left.\mathrm{H}_{2} \mathrm{O}, 8: 2\right)$ column chromatography, Fr. 5 (10.7 g) afforded compounds 4 (4.5 mg), $5(0.5 \mathrm{mg}), \mathbf{6}(0.8 \mathrm{mg}), \mathbf{8}(1.0 \mathrm{mg})$ and $\mathbf{1 0}$ (3.6 mg). Fr.6 (17.0 g) was separated on a silica column (toluene/ $\mathrm{Me}_{2} \mathrm{CO} 95: 5 \rightarrow 3: 7$ gradient system), and then purified by chromatography on a silica gel $\left(\mathrm{CHCl}_{3}-\mathrm{MeOH}, 1: 0 \rightarrow 1: 1\right.$ gradient system) and RP-18 (MeOH- $\left.\mathrm{H}_{2} \mathrm{O}, 8: 2\right)$ to yield compounds 1 (10.0 mg), 3 (4.2 mg), 7 (2.6 mg), 12 (0.9 mg), 13 (4.3 mg), and $14(3.8 \mathrm{mg})$, respectively. Fr.7 (33.8 g) was extensively separated over a silica column (toluene/ $\mathrm{Me}_{2} \mathrm{CO}$ 95:5 $\rightarrow$ 3:7 gradient system) and $\mathrm{RP}-18\left(\mathrm{MeOH}-\mathrm{H}_{2} \mathrm{O}, 3: 7 \rightarrow 7: 3\right.$ gradient system) to afford compounds $2(7.5 \mathrm{mg})$ and $9(0.4 \mathrm{mg})$. Fr. 9 $(10.8 \mathrm{~g})$ was also subjected to silica gel with a gradient elution (toluene- $\mathrm{Me}_{2} \mathrm{CO}, 9: 1 \rightarrow 3: 7$ gradient system) and RP-18 (MeOH$\mathrm{H}_{2} \mathrm{O}, 3: 7 \rightarrow 7: 3$ gradient system) to afford compounds $\mathbf{1 1}(2.7$ $\mathrm{mg})$.

Table 1. ${ }^{1} \mathrm{H}$ and ${ }^{13} \mathrm{C}$ NMR data of compounds 1-2 in acetone- $d_{6}{ }^{a}$

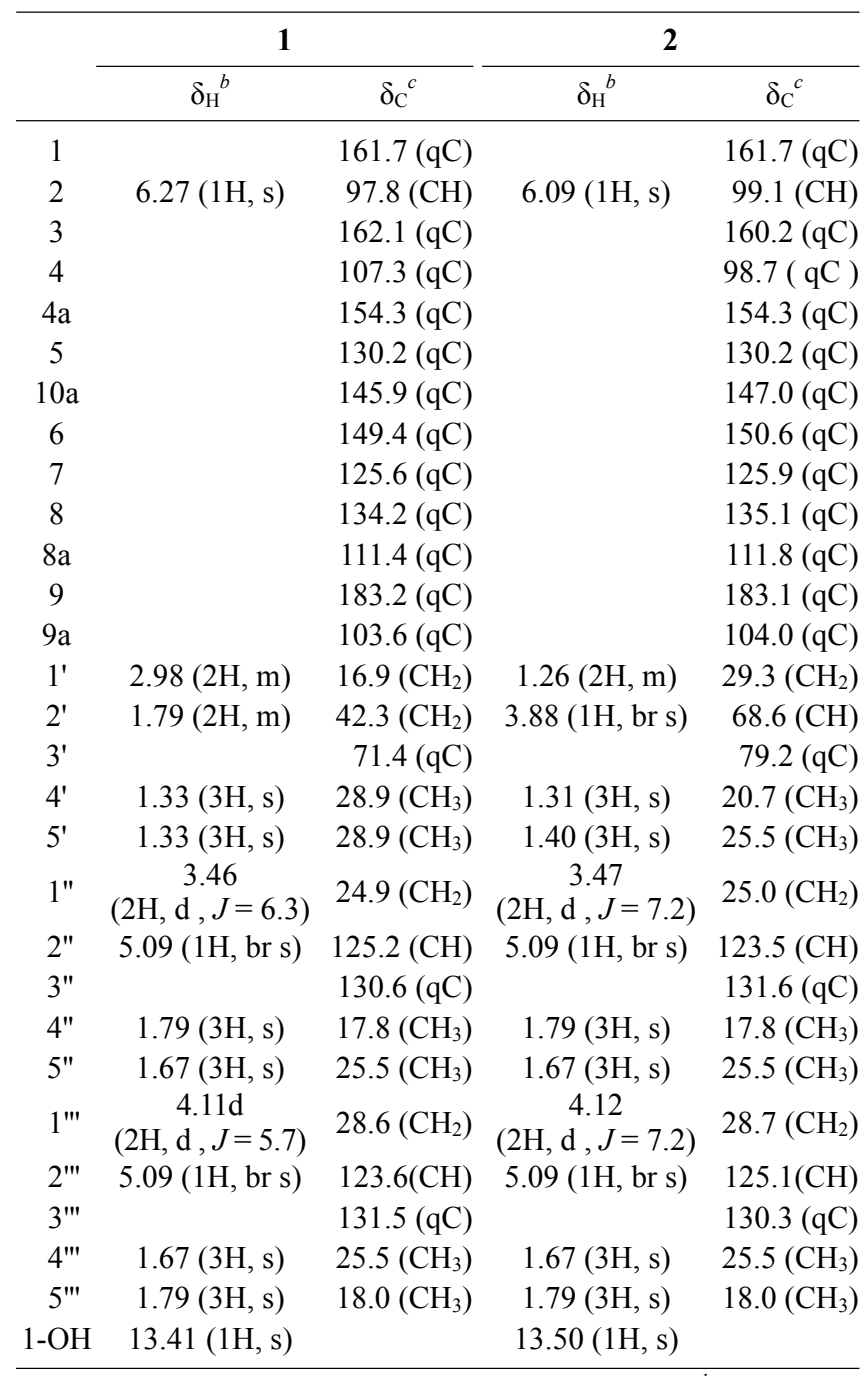

${ }^{a}$ Chemical shifts $(\delta)$ in ppm; Coupling constant $(J)$ in Hz. ${ }^{b}$ Measured in $400 \mathrm{MHz}$ in $\mathrm{Me}_{2} \mathrm{CO}-d_{6}$. ${ }^{c}$ Measured in $100 \mathrm{MHz}$ in $\mathrm{Me}_{2} \mathrm{CO}-d_{6}$. 
1,3,5,6-Tetrahydroxy-4-(3-hydroxy-3-methylbutyl)-7,8-di(3-methyl-2-butenyl) xanthone (1): Yellow amorphous powder; UV $\lambda_{\max }(\mathrm{MeOH}) \mathrm{nm}(\log \varepsilon): 230$ (3.54), 265 (3.53), 346 (3.62); For ${ }^{1} \mathrm{H}$ NMR and ${ }^{13} \mathrm{C}$ NMR (in $\mathrm{Me}_{2} \mathrm{CO}-d_{6}$ ) spectroscopic data, see Table 1; EIMS (70 eV) m/z (\%): $482\left(\mathrm{M}^{+}, 10\right), 464(16)$, 421(60), 409(100), 385(44), 365(68), 353(76), 323(24); HREIMS $m / z 482.2301$ (calcd. for $\mathrm{C}_{28} \mathrm{H}_{34} \mathrm{O}_{7}, 482.2305$ ).

3,4-Dihydro-3,6,7,11-tetrahydroxy-8,9-di-(3-methyl-2-butenyl)-2,2-dimethyl-pyrano-[2,3-c] xanthone (2): Yellow amorphous powder; $\mathrm{UV} \lambda_{\max }(\mathrm{MeOH}) \mathrm{nm}(\log \varepsilon): 230$ (3.52), 265 (3.25), 349 (3.63); For ${ }^{1} \mathrm{H}$ NMR and ${ }^{13} \mathrm{C}$ NMR (in $\mathrm{Me}_{2} \mathrm{CO}-d_{6}$ ) spectroscopic data, see Table 1; EIMS (70 eV) $\mathrm{m} / \mathrm{z}(\%)$ : 480 $\left(\mathrm{M}^{+}, 20\right), 462(4), 437(64), 409(36), 383(100), 74(56)$; HREIMS $\mathrm{m} / z 480.2147$ (calcd. for $\mathrm{C}_{28} \mathrm{H}_{32} \mathrm{O}_{7}, 480.2148$ ).

Acknowledgments. This work was supported by the State key Laboratory of Drug Research (SIMM0901KF-02) and the National Natural Science Foundation of China (No.30670215 ).

\section{References}

1. Bennett, G. J.; Lee, H. H. Phytochemistry 1989, 28, 967.

2. Peres, V.; Nagem, T. J.; Oliveira, D. F. F. Phytochemistry 2000 , 55,683 .

3. Franklin, G.; Conceicao, L. F. R.; Kombrink, E.; Dias, A. C. P. Phytochemistry 2009, 70, 60.

4. (a) Karanjgoakar, C. G.; Rao, A. V. R.; Venkataraman, K.; Yemul, S. S.; Palmer, K. J. Tetrahedron Lett. 1973, 50, 4977. (b) Blount, J. F.; Williams, T. H. Tetrahedron Lett. 1976, 34, 2921. (c) Tandon, R. N.; Srivastava, O. P.; Baslas, R. K.; Kumar, P. Curr. Sci. 1980, 49, 472. (d) Baggett, S.; Protiva, P.; Mazzola, E. P.; Yang, H.; Ressler, E. T.; Basile, M. J.; Weinstein, I. B.; Kennelly, E. J. J. Nat. Prod. 2005, 68, 354 .
5. (a) Konoshima, M.; Ikeshiro, Y.; Miyahara, S.; Yen, K. Y. Tetrahedron Lett. 1970, 48, 4203. (b) Baslas, R. K.; Kumar, P. Curr. Sci. 1979, 48, 814. (c) Baslas, R. K.; Kumar, P. Acta Ciencia Indica 1981, 7, 31

6. Singh, M. P.; Parveen, N.; Khan, N.; Achari, B.; Dutta, P. Fitoterapia 1991, 62, 286.

7. (a) Chanmahasathien, W.; Li, Y. S.; Satake, M.; Oshima, Y.; Ruangrungsi, N.; Ohizumi, Y. Phytochemistry 2003, 64, 981. (b) Chanmahasathien, W.; Li, Y. S.; Satake, M.; Oshima, Y.; Ishibashi, M.; Ruangrungsi, N.; Ohizumi, Y. Chem. Pharm. Bull. 2003, 51, 1332. (c) Han, Q. B.; Qiao, C. F.; Song, J. Z.; Yang, N. Y.; Cao, X. W.; Peng, Y.; Yang, D. J.; Chen, S. L.; Xu, H. X. Chem. Biodivers. 2007, 4, 940.

8. Iinuma, M.; Tosa, H.; Tanaka, T.; Asai, F.; Shimano, R. Phytochemistry 1995, 39, 945.

9. Bayma, J. C.; Arruda, M. S. P.; Neto, M. S. Phytochemistry 1998, 49, 1159.

10. Harrison, L. J.; Leong, L.; Sia, G. L.; Sim, K. Y.; Tan, H. T. W. Phytochemistry 1993, 33, 727.

11. Nguyen, L. H. D.; Vo, H. T.; Pham, H. D.; Connolly, J. D.; Harrison, L. J. Phytochemistry 2003, 63, 467.

12. Ishiguro, K.; Fukumoto, H.; Nakajima, M.; Isoi, K. Phytochemistry 1993, 33, 839 .

13. Fu, P.; Li, T. Z. ; Liu, R. H. ; Zhang, W. ; Zhang, W. D. ; Chen, H. S. Nat. Prod. Res. Dev. 2004, 16, 511.

14. Kosin, J.; Ruangrungsi, N.; Ito, C.; Furukawa, H. Phytochemistry 1998, 47, 1167

15. Luo, L.; Zhang, Y.; Pan, Z. H.; Li, Z. Q. Journal of Yunnan University 2006, 28, 337.

16. Minami, H.; Hamaguchi, K.; Kubo, M.; Fukuyama, Y. Phytochemistry 1998, 49, 1783

17. Nguyen, L. H. D.; Harrison, L. J. Phytochemistry 2000, 53, 111.

18. Inuma, M.; Tosa, H.; Tanaka, T.; Asai, F.; Shimano, R. Heterocycles 1995, 40, 279.

19. Minami, H.; Kuwayama, A.; Yoshizawa, T.; Fukuyama, Y. Chem. Pharm. Bull. 1996, 44, 2103.

20. Zgoda, J. R.; Porter, J. R. Pharm. Biol. 2001, 39, 211. 